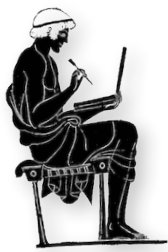

\title{
Remodelando exempla: o paradigma da crueldade e da inclemência no mito do exílio ovidiano
}

Refashioning exempla: the paradigm of cruelty and inclemency in the Ovidian myth of exile

\author{
Cecilia Marcela Ugartemendía ${ }^{1}$ \\ e-mail: cecilia.7u@usp.br \\ orcid: https://orcid.org/0000-0002-0395-7786
}

DOI: https://doi.org/10.25187/codex.v8i2.40367

RESUMO: O objetivo deste artigo é discutir a forma a partir da qual Ovídio constrói paradigmas de crueldade e inclemência que substituiriam conhecidos exempla, propondo aqueles que pertencem a seu exílio como novos exemplos e termos de comparação. Em um primeiro momento, reflete-se sobre a utilização do tropo da hipérbole durante o exílio no recurso da refutatio exemplorum, mediante a qual Ovídio desestima exempla conhecidos para postular instâncias de sua situação de relegado como novos paradigmas. Depois, analisa-se a forma a partir da qual Ovídio constrói seus inimigos, sejam esses seus detratores ou ainda o próprio Augusto, como mais cruéis e inclementes que qualquer outro. Para isto, se dará atenção a Tr. 3.11. 39-54, 5.1.53-54, 5.12.47-48, Pont. 2.9.44 e 3.5.42, trechos a partir dos quais serão analisadas as figuras de Busíride, Fálaris e Perilo como exempla de crueldade e inclemência. Por último, a modo de conclusão, reflito sobre a utilidade dos exempla, que, longe de serem ineficazes como modelos, oferecem como consequência teórica a oportunidade de manipular a tradição literária anterior por meio das comparações e refutationes. Em consequência, Ovídio propõe-se a si mesmo, e a sua situação, como autoridade.

PALAVRAS-CHAVE: exílio ovidiano; exempla; hipérbole; refutatio exemplorum

\begin{abstract}
The aim of this paper is to discuss the way in which Ovid builds paradigms of cruelty and inclemency that would replace known exempla, proposing those belonging to his exile as new examples and as new terms of comparison. First, I reflect on the use of the hyperbole trope during exile on the recourse to the refutatio exemplorum, through which Ovid dismisses known exempla to postulate instances of his situation in exile as new paradigms. Then, I analyze how Ovid presents his enemies, either his detractors or even Augustus, as crueler and more inclement than any other. For this, I turn to Tr. 3.11. 39-54, 5.1.53-54, 5.12.47-48, Pont. 2.9.44 and 3.5.42, from which I examine the figures of Busiris, Phalaris and Perillus as examples of cruelty. Finally, in conclusion, I reflect on the usefulness of exempla, which, far from being ineffective as models, offer the opportunity to manipulate the previous literary tradition by means of comparisons and refutationes. As consequence, Ovid proposes himself, and his situation, as authority.
\end{abstract}

KEYWORDS: Ovidian exile; exempla; hyperbole; refutatio exemplorum

\footnotetext{
${ }^{1}$ Doutoranda do Programa de Pós-Graduação em Letras Clássicas da Faculdade de Filosofia, Letras e Ciências Humanas da Universidade de São Paulo, São Paulo, Brasil, sob a orientação do Prof. Dr. Alexandre Pinheiro Hasegawa. Bolsista FAPESP (Proceso 2017/01934-8).
} 


\section{Introdução}

Sabemos pouco sobre o exílio de Ovídio além do que ele mesmo conta nos poemas que fazem parte dos Tristia e das Epistulae ex Ponto ${ }^{2}$, ambas coleções compostas durante o período em que o poeta morou como relegatus em Tomos, desde o ano $8 \mathrm{~d}$. C. até sua morte no $17 \mathrm{~d}$. C. Nessas duas obras, Ovídio lamenta sua condição de relegatus e se defende dos duo crimina, causas da condenação: carmen et error (Tr. 2.207). Há certo consenso - sustentado pelo testemunho do próprio Ovídio em Tr. 2.211-212 (entre outros lugares) - em entender que o carmen teria sido a Ars amatoria, que iria contra as leis augustanas que procuravam preservar o matrimônio e a famíliả ${ }^{3}$. Há algumas conjecturas sobre qual poderia ter sido o error, mas pouca certeza a respeito ${ }^{4}$. Segundo uma dessas hipóteses, Ovídio teria visto algo que não deveria. Todavia, a hipótese é sustentada apenas por meio das referências diretas a isso nos próprios poemas (a exemplo de Tr. 2.103-110) e por vários paralelos estabelecidos por Ovídio entre sua situação e as personagens míticas que sofreram um castigo precisamente por ter visto o que não deviam. É o caso, por exemplo, de Acteão. A identificação de Ovídio com a versão do mito que ele oferece em Met. 3. 138-252 tem sido muito discutida pela crítica $^{5}$. Este é um dos melhores exemplos para ilustrar a forma a partir da qual Ovídio trabalha com os mitos já conhecidos para, por meio da sua remodelação, defender-se da condenação. Em síntese, Acteão viu, de forma involuntária, a deusa Diana enquanto ela tomava um banho, nua, em uma fonte. Como castigo, foi transformado em um cervo, mantendo, porém, a capacidade cognitiva de ser humano. Portanto, ele encontrou-se preso no corpo do animal; consciente, mas mutus ${ }^{6}$, incapaz de

\footnotetext{
2 Sobre esses poemas em geral, ver Evans (1983), Nagle (1980), Williams (1994), Tola (2004), Claassen (2008), McGowan (2009).

${ }^{3}$ Cf. Nagle (1995, p. 3). A autora arrisca afirmar que o carmen não seria a Ars amatoria, mas as Metamorphoses, uma vez que "o que ele 'viu', que se reflete nas [Metamorphoses], foi a construção de um mito na propaganda augustana e a manipulação da ideologia, que disfarçou a introdução de uma nova forma de monarquia como a restauração de uma forma republicana de governo" " what he 'saw', which is reflected in the [Metamorphoses], was the working of a myth in Augustan propaganda and the manipulation of ideology, which disguised the introduction of a new form of monarchy as the restoration of Republican forms of goverment”) (as traduções de línguas modernas são próprias). A interpretação de Nagle é bastante ousada e refutável, devido a que Ovídio menciona de forma específica a Ars amatoria em Tr. 2. 211-212 como causa de condenação, assim aponta também Ingleheart (2006, p. 64), que considera a leitura de Nagle "a perverse view" ("um ponto de vista perverso").

${ }^{4}$ Sobre o Carmen et error, ver, i. a., Syme (1978, pp. 215-22), Green (1982). Qual seria o error que levou o poeta ao exílio segue sendo um problema difícil de elucidar. Ver Della Corte (1990) sobre diferentes hipóteses. Inclusive, tem sido proposto entender carmen et error como uma hendíade, que poderia ser lida como "o erro do poema" (THIBAULT, 1964, pp. 36-37 apud INGLEHEART, 2006, p. 64 y NAGLE, 1995, p. 3).

${ }^{5}$ Ver, i. a., Della Corte (1990, p. 50), Putnam (2001), Cardoso (2005), Ingleheart (2006), Tola (2008), Natoli (2017, pp. 41-45).

${ }^{6}$ Sobre o termo mutus em Ovídio, ver o estudo completo de Natoli (2017). Esse autor reflete sobre as consequências da perda da capacidade de falar nas Metamorphoses e nos poemas do exílio, e de como se tenta resolver o problema da comunicação utilizando outros meios, entre os quais a escrita demonstra ser o mais apropriado.
} 
se expressar. A analogia entre o relegado que viu algo que não devia e Acteão, quem errou de forma similar, é apenas um dos tantos usos de exempla míticos aproveitados pelo poeta para descrever sua situação.

Este artigo encontra sua delimitação na forma com que Ovídio utiliza exempla de crueldade conhecidos - como as figuras de Busíris, Fálaris e Perilo -, para caracterizar o comportamento de seus detratores e a atitude de Augusto, quem se mostra inclemente com o poeta, contrariamente ao esperado dele e da famosa clementia principis. Ovídio compara seus detratores e o próprio princeps com os míticos reis. A partir dessa comparação, o poeta conclui que seus opositores são, em verdade, mais cruéis e inclementes que os já conhecidos exempla, o que levaria a descartá-los como referência. Para fins desta análise, serão estudadas as cinco instâncias nas quais as figuras de Busíris, Fálaris e/ou Perilo aparecem nas coletâneas de livros dos Tristia e das Epistulae ex Ponto.

\section{O hiperbólico uso da hipérbole como caminho à autoridade poética}

Para expressar sua constante queixa sobre os males que suporta, nas elegias de exílio Ovídio recorre muito frequentemente à hipérbole. São muitas as instâncias nas quais as descrições hiperbólicas de Tomos adicionam caráter patético à construção da cena do relegado em terra adversa. Há um exemplo disso em Tr.3. 10, poema em que se descreve a paisagem danubiana e a cidade de Tomos. Ali, entre os versos 25-50, Ovídio desenvolve uma extensa passagem de grande conteúdo hiperbólico. É chamativa, nessas linhas, a destreza e o domínio da língua, pela diversidade na seleção léxica para se referir ao campo semântico "água" para ilustrar a ferocidade do frio congelante: rivus (v. 25), lacus (v. 26), aqua (v. 26, 30, 38, 42, 48), amnis (v. 27), fretum (v. 28), Hister (v. 29), mare (v. 30), unda (v. 33, 40), pontus (v. 37), aequor (v. 39), fluctus (v. 46). Não apenas os rios, o mar também congela diante do frio extremo (Tr. 3. 10. 37: vidimus ingentem glacie consistere pontum ["vi o ingente mar solidificarse"]). Ovídio, consciente do hiperbólico do discurso, reconhece a dificuldade de se crer em seu relato: vix equidem credar (v. 35 ["de fato, dificilmente me crerão"]). A defesa do discurso frente a possíveis detratores funciona como outra ferramenta em sua argumentação. Apesar disso, Ovídio não escapou sequer aos estudiosos de sua obra, dentre os quais se destaca Fitton Brown (1985), quem expressa seu ceticismo a respeito do exílio de Ovídio ao analisar justamente as passagens hiperbólicas de sua descrição. De fato, por ser uma situação que foge ao comum e que provoca descrições hiperbólicas

\footnotetext{
7 Ovídio teve ampla formação retórica. Sêneca, o velho, em suas Controversiae, confere em mais de uma oportunidade as técnicas declamatórias do jovem poeta. A respeito, ver Fantham (2009, pp. 27-29). Mais sobre a formação retórica de Ovídio em Schiesaro (2006), Auhagen (2007). O uso de exempla é prática comum tanto em poesia como em retórica. É possível que seu uso em poesia tenha relação com a educação dos romanos nas escolas de declamação (LAROSA, 2020). Sobre o uso de exempla nos discursos declamatórios, ver Poel (2009).
} 
(pelo menos, segundo diz Ovídio, apenas parecem hiperbólicas, já que refletiriam a realidade), o poeta deve defender a veracidade de suas palavras, fazendo referência aos sentidos e colocando-se como testemunha de primeira mão. Por exemplo, destaca-se de forma constante o poder do sentido da vista $^{8}$ : vidimus... (v. 37), nec vidisse sat est, ... calcavimus ... (v. 39), vidimus (v. 49). Isso confere validade ao relato (Tr. 3. 10. 36: ratam debet testis habere fidem, "a testemunha deve ter credibilidade") ${ }^{9}$. A hipérbole, mais do que um recurso, parece ser apenas uma consequência iniludível na descrição da situação do exilado. O ornamento retórico se faz necessário e inevitável e isso o poeta o reconhece. É por isso que pede licença para relatar o extraordinário e se justifica dizendo, em Tr. 5. 6. 42, crede mihi, vero est nostra querela minor ["crê em mim, minha queixa é menor do que a realidade"] ${ }^{10}$.

Ligadas às descrições hiperbólicas, os adynata se multiplicam ao longo das duas obras, inclusive mais do que em qualquer outro autor do corpus de poetas latinos ${ }^{11}$. Essas descrições impossíveis se aproximariam cada vez mais da situação do poeta ${ }^{12}$. Da mesma forma, as reiteradas enumerações da quantidade de males e do tamanho do sofrimento padecido pelo relegatus chega a comparações hiperbólicas ${ }^{13}$. Como bem define Davisson,

Ovídio justapõe adynata convencionais com sua própria experiencia para insistir em que seu sofrimento, que soa impossível, é desafortunadamente real; para sugerir que a deslealdade de seu destinatário, que deveria ser inconcebível, é desafortunadamente possível; e, da mesma maneira, para sugerir que seus destinatários podem ter mostrado uma quase inconcebível falta de simpatia (DAVISSON, 1980, p. 128) ${ }^{14}$.

\footnotetext{
${ }^{8}$ Ovídio aborda a descrição de Tomos, de sua gente, costumes, paisagem e estilo de vida em um grande número de trechos, o que leva a pensar em um estilo de escritura etnográfica ovidiana, uma forma a mais em que o poeta ganha autoridade. Como etnógrafo de Tomos, Ovídio retoma convenções formulares da etnografia (sobre essas convenções, ver Woolf, 2001), e por isso sua descrição da Cítia não se afasta muito da de Virgílio, que por sua vez é similar em sua descrição às representações tradicionais da Cítia que remontam a Heródoto 4. 28. A principal diferença com Virgílio, todavia, é que Ovídio pode citar outra convenção da escritura etnográfica: a capacidade de "autópsia" (WOOLF, 2001, p. 14). Ter visto, como testemunha ocular direta, o que está a descrever outorga um caráter diferencial à sua descrição. A reivindicação do poder da visão como prova de autoridade se encontra também nos historiógrafos. Veja-se, por exemplo, Heródoto, 1. 5-13, ou Políbio, Hist.12.27. Para uma discussão sobre o sentido da observação visual e sua importância para a historiografia, ver Hasegawa (2017, esp. pp. 12-14), que menciona essas passagens citadas, além de oferecer outros exemplos.

9 Mais sobre esta epístola em Ugartemendía (2020).

${ }^{10} \mathrm{O}$ apelo ao público para que, apesar do extraordinário, possa acreditar no que se diz enfatizando o recurso à autópsia é função comum tanto em etnógrafos e historiógrafos como em poetas. Veja-se, por exemplo, Horácio, Carm. 2. 19. 1-2: Bacchum in remotis carmina rupibus / vidi docentem, credite posteri ("tenho visto Baco em apartados penhascos / ensinando suas canções, crede-me, futuros...").

${ }^{11}$ Claassen (2008, p. 70).

${ }^{12}$ Sobre adynata na poesia do exílio ovidiano, ver particularmente o estudo de Davisson (1980) e, antes dele, Canter (1930).

${ }_{13}$ Ver, por exemplo, Tr. 1. 47-50, 3. 2. 19-20, 5. 6. 35-36, 42.

14 "Ovid juxtaposes conventional adynata with his own experience to insist that his sufferings, which sound impossible, are unfortunately real; to suggest that his addressees' disloyalty, which should be inconceivable, is unfortunately possible; and likewise to suggest that his addressees may have shown a nearly inconceivable lack of sympathy."
} 
O discurso hiperbólico do sofrimento ganha protagonismo nas comparações de Ovídio entre sua presente situação e exempla históricos e mitológicos. Esse tipo de descrição é coerente com a classificação de hipérbole oferecida por Quintiliano, segundo o qual o recurso não é mais do que um apropriado exagero da verdade (Inst. 8.6.67: est autem haec decens veri superiectio). Podemos encontrar claro exemplo disto naquelas passagens em que o poeta compara suas desgraças com as das personagens Níobe, Jasão ${ }^{15}$, Acteão ou Ulisses ${ }^{16}$. Com essas comparações, Ovídio eleva-se a um nível mítico, introduzindo uma tensão de grandeza épica na elegia (TISSOL, 2014, p. 9) ${ }^{17}$. Essa forma de elevação e de recurso retórico também gerou críticas por parte daqueles estudiosos que não veem a hipérbole como um recurso poético, mas como algo que na verdade retira a verossimilhança de um discurso que pretende se mostrar como sério ${ }^{18}$. Essa dissonância com o uso da hipérbole é muito bem descrita por Hardie (1986, p. 241), quem conclui que

[a] hipérbole não é um tropo que atualmente esteja bem visto: ofende a ideia moderna de verossimilhança e sinceridade, já que é considerado como um sinal de falsidade tanto objetiva como subjetiva, isto é, que diz respeito tanto ao mundo externo como ao psicológico do observador ${ }^{19}$.

A tradição mítica, que combina explicitamente a narrativa com a autoridade cultural ${ }^{20}$, é tão frequente nos poemas de exílio como nas elegias amorosas ovidianas. Com efeito, muitos exempla míticos são versões frequentemente utilizadas por Ovídio em seus trabalhos anteriores. Aqui, porém, em várias ocasiões, os exempla parecem ineficazes, seja porque a penúria do poeta não parece encontrar paralelo nos exemplos citados, seja porque são mencionados apenas para, posteriormente, descartá-los como referência, operando a refutatio exemplorum ${ }^{21}$. Desse modo, Ovídio rejeita exempla de sofrimento para postular a ele mesmo, por meio da comparação, como exemplum de sofrimento do exilado, outorgando a uma situação subjetiva uma dimensão universal. A mitologia serve agora não como exemplo per se, mas como um ponto de comparação que permite elevar a presente situação do poeta a um nível paradigmático.

\footnotetext{
${ }^{15}$ Sobre as figuras de Jasão e Ulisses, ver Tola (2000), que propõe entendê-las, junto com a de Medeia, como o imaginário mítico central desses poemas. Sobre a figura de Ulisses, ver, em especial, Davisson (1982).

16 Ver nota 5.

17 "elevates himself, at least for the moment, to the mythic level and introduces a strain of epic grandeur into elegy."

18 Sobre os efeitos cómicos na obra do exílio ovidiano, ver Amann (2006); particularmente, pp. 104-108 para a análise de efeito de comicidade que surge da comparação entre Ovídio e Ulisses.

19 "Hyperbole is not a trope currently in favour: it offends against modern ideals of verisimilitude and sincerity, for it is taken as the sign of a falseness both objective and subjective, that is, with regard both to the external world and to the psychology of the observer."

20 Scanlon (2007, p. 9).

${ }^{21}$ Bernhardt (1986, p. 40).
} 
Nos casos em que Ovídio aplica a refutatio exemplorum, a hipérbole parece se produzir

pelo simples recurso de explorar a progressiva diminuição em escala e poder à medida que nos movemos dos remotos eventos da cosmogonia até os demasiado limitados poderes dos homens de hoje; o movimento pode ser do mito à lenda, da lenda à história ou do mito à história (HARDIE, 1986, p. 252)22.

No que concerne aos poemas do exílio, nas comparações entre sua situação e os diferentes exempla mitológicos, Ovídio equipara situações, lugares e pessoas de um presente que seria verossímil com aqueles que pertencem a uma situação mítica, gerando assim um efeito hiperbólico na construção retórica de seu discurso.

A seguir, será discutida a configuração ovidiana de um novo paradigma do inimigo cruel. Para tanto, será analisada uma série de refutationes de exempla apresentados pelo poeta com o intuito de propor um novo modelo de acérrimo inimigo, o qual ele mesmo deve enfrentar no exílio.

\section{A construção do inimigo do poeta como paradigma de crueldade}

Ao propor um novo paradigma de exilado, sofredor e vítima de injustiça, Ovídio constrói também outros papéis paradigmáticos que interagem com ele. Da mesma forma em que descreve os infortúnios de seu dia-a-dia, a adversidade do clima em Tomos, os povos selvagens que o circundam, também há personagens cujos papeis são destacados no mito do exílio. É o caso, por exemplo, de Fábia, a esposa do poeta, reiterada destinatária de suas cartas. Ela também é modelada como personagem paradigmática. Esse caráter modelar tem chamado a atenção de críticos que entendem a figura de Fábia não como personagem histórica, mas como uma criação idealizada da esposa ideal ${ }^{23}$. Porém, a análise dessa personagem, por sua frequência de aparição e a importância que ganha no corpus, será tema de abordagem em outra oportunidade. O papel que me interessa destacar neste trabalho é o dos inimigos, cuja crueldade, diz Ovídio, é incomparável.

\footnotetext{
22 "may thus be produced by the simple device of exploiting the progressive diminution in scale and power as we move from the remotest events of cosmogony to the alltoo-limited powers of present-day men; the move may be from myth to legend, from legend to history, or from myth to history."

${ }^{23}$ Natoli (2017, p. 129): "recentemente, análises da esposa do exilado seguiram a mesma linha dos estudos mais amplos sobre a literatura de exílio, passando de um ângulo mais histórico (Helzle, 1989) a um mais literário (Hinds 1998; Petersen 2005; Reeber 2014). Em vez de associar a esposa do exilado a uma das esposas reais, históricas de Ovídio, os estudos recentes têm identificado cada vez mais a esposa como amálgama de personae elegíacas: a instável puella, a domina elegíaca e a matrona. Mais ainda, Joy Reeber (2014) chegou ao ponto de equiparar a esposa com uma representação metafórica de um corpus físico e literário na mesma forma com que Maria Wyke (2002) descreveu Cíntia em Propércio" ("recently, analyses of the exile's wife have followed the same lines as scholarship on the exile literature more broadly, shifting from a more historical (HELZLE, 1989) to a more literary (HINDS, 1998; PETERSEN 2005; REEBER, 2014) angle. Instead of associating the exile's wife with one of Ovid's actual, historical wives, recent scholarship has increasingly identified the wife as an amalgam of elegiac personae: the fickle puella, the elegiac domina, and the matrona (PETERSEN, 2005). Moreover, Joy Reeber (2014) has gone so far as to equate the wife with a metaphorical representation of a physical and literary corpus in the same way Maria Wyke (2002) has described Cynthia in Propertius").
} 
As figuras cuja aparição é frequente e das quais Ovídio se serve para ilustrar o caráter de seus detratores e críticos são as dos reis Busíris, Fálaris e a do construtor Perilo (considerado vítima deste último, embora também ele mesmo seja um exemplum de crueldade). Claassen, em detalhado estudo sobre a aparição de diferentes figuras mitológicas nos poemas de exílio, destaca as figuras de Busíris e Fálaris como personagens dominantes por sua frequência de aparição ${ }^{24}$. Busíris aparece em Tr. 3.11.39 e Pont. 3.6.41. Por sua vez, Fálaris é citado em Tr. 3.11.42, 51; 5.1.53; Pont. 2.9.44 e 3.6.42. Busíris foi o rei do Egito, a quem um profeta de Chipre tinha aconselhado sacrificar um estrangeiro para apaziguar a ira de Júpiter, que tinha causado graves secas no reino. Após ouvir o conselho, o rei ordenou que o profeta fosse imediatamente sacrificado, por sua condição de estrangeiro. Fálaris, por sua vez, foi um tirano de Agrigento, que, como se conta nesses versos, permite que Perilo experimente sua própria invenção: um toro de bronze no qual poderiam ser incinerados aqueles a quem Fálaris quisesse castigar. Assim, Perilo torna-se o primeiro a ser incinerado.

Ovídio já tinha citado, de forma conjunta, esses dois reis como exempla em Ars 1. 647-656, passagem na qual o praeceptor instrui sobre enganar as mulheres que enganam ${ }^{25}$. Ali, os reis são exempla não de crueldade, mas de justiça. O praeceptor fecha a passagem com a seguinte reflexão:

Iustus uterque fuit: neque enim lex aequior ulla est, quam necis artifices arte perire sua (Ars 1. 655).

[“Um e outro foram justos, e nenhuma lei é mais justa do que [isso:] que os artífices de morte pereçam pela sua arte”.]

Nos Tristia, Busíris e Fálaris são mencionados com um fim diferente. Sua atitude não é considerada justa, mas cruel. A eles se soma também a figura de Perilo, quem cumpre uma função dupla: como criador do touro de bronze é algoz, mas, por ser o primeiro em provar seu invento, é vítima da severidade de Fálaris. Portanto, na análise que se oferece a seguir, adiciono à lista de exempla citada por Claassen a passagem de Tr. 5.12.47, que, em princípio, refere-se a Perilo, mas nela também se pode fazer alusão a Fálaris e a um primeiro momento da analogia entre esse rei e Augusto (isso se repete nas passagens seguintes em que reaparecem as personagens).

Em Tr. 3. 11, poema de caraterísticas jâmbicas, Ovídio se dirige a seus detratores durante o exílio $^{26}$. Nos versos 39-54, o poeta caracteriza seu rival enfatizando o adjetivo saevior ("mais cruel”) ao

\footnotetext{
${ }^{24}$ Claassen (2008, p. 282). Segundo a lista da autora, Busíris aparece em Tr. 3.11.39 e Pont. 3.6.41; Fálaris é citado em Tr. 3.11.42, 51; 5.1.53; Pont. 2.9.44 e 3.6.42. Nesta análise, adiciono à lista a passagem correspondente a Tr. 5.12.47, que, apesar de referir-se a Perilo, dispara a possibilidade de pensar uma alusão velada a Fálaris.

${ }_{25}$ Tanto Busíris como Fálaris aparecem também em outras obras de Ovídio: Busíris, em Met. 9. 183 e Ep. 9. 69; Fálaris, em $I b .439$.

${ }^{26}$ Outras instâncias de poemas de caráter jâmbico no exílio são Tr. 3. 11; 4. 9; 5. 8. Pont. 4.3, 16, além de todo o Ibis. Inclusive, conjectura-se que o destinatário de Tr. 3.11 poderia ser o mesmo de Ibis (BAEZA ANGULO, 2005, 104).
} 
começo do hexâmetro, reforçado pela anáfora do termo no quinto pé do mesmo verso. Dessa forma, Ovídio abre a comparação hiperbólica entre inimigos exemplares e seu próprio inimigo, dizendo que seu detrator é mais cruel do que Busíris e do que Perilo, o inventor do touro de bronze.

Saevior es tristi Busiride, saevior illo, qui falsum lento torruit igne bovem,

quique bovem Siculo fertur donasse tyranno, et dictis artes conciliasse suas:

"munere in hoc, rex, est usus, sed imagine maior, nec sola est operis forma probanda mei.

Aspicis a dextra latus hoc adapertile tauri?

Hac tibi, quem perdes, coniciendus erit.

Protinus inclusum lentis carbonibus ure: mugiet, et veri vox erit illa bovis.

Pro quibus inventis, ut munus munere penses, da, precor, ingenio praemia digna meo".

Dixerat. At Phalaris "poenae mirande repertor, ipse tuum praesens imbue" dixit "opus".

Nec mora, monstratis crudeliter ignibus ustus exhibuit geminos ore gemente sonos.

["Mais cruel é do que o severo Busíris, mais cruel do que aquele que assou com fogo lento um falso boi [40], e que, conta-se, doou o boi ao tirano de Sićlilia, e recomendou suas artes com estas palavras: 'neste presente, rei, há uma utilidade, mas maior do que sua imagem, e não deve ser apreciada apenas a forma de minha obra. Vês à direita este lado do touro que pode ser aberto? [45] Por aqui deverá ser arrojado quem tu destruas. Imediatamente queima-o [aquele que está] encerrado com carvões lentos: mugirá e a voz será [como] aquela do verdadeiro boi. Por este invento para compensar um presente com um presente, dê-me, por favor, prêmios dignos para meu engenho' [50]. Tinha dito. Mas Fálaris disse: 'admirável inventor deste castigo, experimenta tu mesmo, primeiro, tua obra'. Sem demora, consumido cruelmente pelas chamas mostradas, produziu sons duplos com sua gemente boca".]

$\mathrm{Na}$ comparação com Perilo, Ovídio sugere a seu inimigo que ele poderia receber castigo similar ao que ele quer infligir. Inclusive, o poeta, nos versos 67-68, adverte: humanaeque memor sortis, quae tollit eosdem / et premet, incertas ipse verere vices ["recorda a fortuna humana, que eleva e afunda aos mesmos. Teme tu mesmo as incertas eventualidades"]. Dessa forma, fica latente a ideia de que esse inimigo poderia sofrer a represália que lhe corresponde pela sua crueldade. Destaca-se também o fato de que o episódio de Fálaris e Perilo ocupa o maior número de versos dedicados à exposição de um exemplum em todo Tristia. Isso enfatiza a relevância desse exemplum e leva a pensar que, por trás dessa analogia, o poeta quer dizer mais do que faz de forma explícita. Vejamos por quê. 
Em Tr. 5. 1. 53-54, encontramos a segunda aparição de Fálaris. Dessa vez, o rei de Agrigento novamente é superado em crueldade, mas agora não por um inimigo, e sim por um amigo do poeta. A dimensão hiperbólica do lamento ovidiano leva-o a se queixar de que nem sequer os amigos lhe permitem lamentar a má fortuna. O próprio amigo é caracterizado como durior hoste, depois de ter sido comparado com Fálaris, quem, segundo o poeta, ao menos permite que suas vítimas emitam queixas enquanto estão sendo incineradas:

\section{ipse Perilleo Phalaris permisit in aere}

edere mugitus et bovis ore queri.

[“O próprio Fálaris permitiu emitir gemidos no bronze de Perilo e se queixar pela boca do boi”.]

Com esses exemplos, já podemos ver a forma com que Ovídio opera a refutatio exemplorum. Dessas comparações propostas, entende-se que as figuras de Busíris, Fálaris e Perilo já não bastam como paradigmas de crueldade, uma vez que, não apenas seus inimigos, mas também os amigos mostram-se saeviores e duriores do que essas personagens. Portanto, temos novos modelos de crueldade, dos quais o poeta é vítima.

Ao longo do corpus, a principal figura que podemos encontrar como oposta à do poeta não são seus detratores, os invejosos ou um possível inimigo. É o próprio Augusto. A falta de clemência ${ }^{27}$ do princeps é um leitmotiv nos poemas de exílio ovidianos e dá vazão ao poeta para comparar Augusto com figuras paradigmáticas pela severidade, mais precisamente com a figura de Fálaris.

O primeiro momento em que se insinua essa analogia é em Tr. 5. 12. 47-48. Nesse dístico, a referência a Fálaris e a Augusto é oblíqua e surge, em verdade, do paralelismo, este sim explícito, entre Perilo e o poeta:

\section{Utque dedit iustas tauri fabricator aëni, sic ego do poenas artibus ipse meis.}

["E assim como o inventor do touro de bronze pagou um justo castigo, eu mesmo pago o castigo pelas minhas artes".]

\footnotetext{
${ }^{27}$ A clementia principis, um dos grandes atributos de Augusto, era destacada na propaganda augustana. O próprio princeps lhe dedica umas linhas nas Res Gestae 3. 1-2: bella terra et mari civilia externaque toto in orbe terrarum saepe gessi, victorque omnibus veniam petentibus civibus peperci. Externas gentes, quibus tuto ignosci potuit, conservare quam excidere malui ("amiúde, levei a cabo guerras civis e externas por terra e por mar em todo o orbe do mundo, e, vencedor, fui indulgente com todos os cidadãos que pediram perdão. Os povos estrangeiros, que puderam ser perdoados de forma segura, preferi preservá-los a destruí-los"). Mais sobre a clementia principis e sua representação nos poemas de exílio no comentário de Ingleheart ao livro 2 dos Tristia (2010, ad loc.), no comentário de Gaertner a Epistulae ex Ponto 1 (2005, ad loc.) e Dowling (2006), em cujo livro estuda as relações entre clemência e crueldade no mundo romano, especialmente, pp. 109-122, nas que analisa o tratamento que Ovídio dá à clementia principis após a relegatio.
} 
Ao menos a analogia apresentada por Ovídio é ousada. Se ele é como Perilo e recebe uma punição (poenas) pelas suas artes (leia-se por artes os três livros da Ars amatoria), logo Augusto seria semelhante a Fálaris, por ser o algoz. Aqui há rastros de ironia ovidiana ao atacar o princeps por meio da caracterização pejorativa que se depreende da aproximação com o tirano. A analogia é mais pungente ainda ao levar em conta que, diferentemente do que acontece em outros lugares, Augusto é comparado não apenas com uma divindade, mas com um tirano, mortal, famoso por sua crueldade.

A aproximação de Augusto à figura de Fálaris, associados pela sua falta de clemência, reiterase em Ex Ponto 2. 9. Nesse poema o poeta escreve ao rei trácio Clóvis, pedindo ajuda para suportar o exílio. No verso 22, Ovídio assinala que Clóvis responde pedidos de ajuda, ao igual que o deus o faz (sendo esse deus Augusto). Ovídio remete aqui a um motivo tratado durante o helenismo, que faz parte da ideologia da clementia: a configuração da monarquia como uma instituição que ajuda a quem mais necessita ${ }^{28}$. Trata-se das obrigações de quem detém o poder, o que justifica sua legitimidade quando usa esse poder de maneira benéfica. Uma das formas de uso seria ajudar a quem precisa de auxílio. Para convencer Clóvis a ajudá-lo no exílio, o poeta expõe exempla de personagens que não apenas negaram um tipo de ajuda ou recompensa a quem solicitou, mas que o fizeram de maneira cruel. Entre eles encontra-se novamente Fálaris (v. 44, quive repertorem torruit arte sua ["ou quem queimou o autor com sua própria arte"). Galasso não vê uma alusão a si mesmo por parte do poeta ${ }^{29}$. Todavia, considerando a frequência de aparição do exemplo de Fálaris - que, como mencionado acima, é das mais altas em todo o corpus -, as propostas prévias de um paralelismo entre o poeta e Perilo, e o fato de que grande parte de Pont. 2.9 gira em torno da ideia de comparar Clóvis e Augusto no tocante a suas atribuições e obrigações como governantes, é difícil ignorar uma nova e possível assimilação Fálaris - Augusto / Perilo - Ovídio. Mais ainda, há aproximação de Augusto com outros tiranos que também são exemplos de crueldade: Antífates (41), Apolodoro de Cassandria (43) e Alexandre de Feras (43). Clóvis e seu pai não são como esses tiranos; os de Trácia sim respondem ao pedido de ajuda. Por omissão, Augusto se aproxima novamente a figuras de tiranos mortais, por não oferecer nenhum auxílio nem demonstrar clemência.

Há uma última menção a Fálaris e Busíris em Ex Ponto 3. 6. 42. Esse poema, à diferença do que acontece com o restante da coletânea, tem a particularidade de ocultar o nome do destinatário. A razão para evitar nomeá-lo, segundo aponta Ovídio, seria o temor de seu amigo sofrer um castigo pela relação com o exilado (5-14). Ovídio escreve essa breve carta lhe explicando que não deveria se preocupar com uma represália por parte de Augusto, acentuando continuamente a clementia Caesaris

\footnotetext{
${ }^{28}$ Galasso (1995, ad loc.).

${ }^{29}$ Galasso (1995, ad loc.).
} 
(7). Não obstante, pode-se dizer que o exagero em ressaltar constantemente a clemência de Augusto pode ser entendido como um caso de hipérbole em chave irônica ${ }^{30}$. Os deuses, diz Ovídio (21-22), perdoam. César é melhor do que os deuses (23-24), ergo, deve perdoar. Mais ainda, ao contrário de Júpiter, Marte ou Netuno (35-36), os quais não podem reviver aqueles que pereceram por causas de seus castigos, César sim tem a habilidade superior de fazer alguém reviver ou aliviar uma punição (37-38). Poderia, por tanto, aliviar o castigo do poeta sem maiores problemas, porém não o faz. Todo esse louvor e elevação hiperbólica de Augusto, ao compará-lo e colocá-lo por cima dos deuses do Olimpo, termina com uma contraposição de Augusto com, mais uma vez, Busíris e Fálaris, que aparecem como antítese do princeps (41-42):

\section{Forsitan haec domino Busiride iure timeres aut solito clausos urere in aere uiros.}

[“Talvez isto o temerias com razão com Busíris como senhor ou com quem costumava queimar homens encerrados no bronze".]

Se, como já disse, tomamos o discurso sobre a clemência de Augusto em chave irônica, a aparente comparação antitética entre Augusto e os tiranos ganha outra luz. O que parecia ser uma contraposição, aproxima-se mais a uma irônica comparação sobre a falta de clemência. Além disso, o que possibilita a leitura irônica é o fato de que, em uma coletânea na qual todos os poemas têm formato de epístola e levam o nome do destinatário, apenas uma delas seja exceção. Isso permite ponderar que se trataria de uma carta aberta para denunciar a falta de liberdade de expressão, menosprezando a figura de Augusto.

\section{Conclusão}

Ao analisar diferentes passagens dos poemas de exílio nas que Ovídio se compara com diferentes personagens míticas, Graf (2002) conclui que, embora os exempla continuem funcionando como ponto de comparação, há uma quebra nos paradigmas míticos à medida que demonstra que sua situação é única. A observação é acertada e nas páginas anteriores procuramos demonstrar justamente o mecanismo mediante o qual Ovídio expõe essa quebra, tomando como exemplo determinado a figura do inimigo. Todavia, o autor continua dizendo: "os mesmos exemplos que foram úteis no mundo do amor urbano (...) já não podem efetivamente auxiliar na compreensão do que está acontecendo. O exílio de Ovídio marca o fim da utilidade da mitologia” (GRAF, 2002, pp. 114-115) ${ }^{31}$.

\footnotetext{
${ }^{30}$ Ver Wilson (2017) para análise da definição e diferenças entre hipérbole, ironia e hipérbole irônica.

31 "The very exempla that were useful in the world of urbane love (...) are no real help in understanding what is going on. Ovid's exile signals the end of mythology's usefulness."
} 
Aqui preciso divergir. Ovídio não está dizendo que a mitologia tenha perdido sua utilidade. O que ele faz é se aproveitar de sua autoridade como poeta para fazer comparações e expressar as diferenças, em muitos casos hiperbólicas, entre sua situação atual e aquela descrita na tradição mítica. Essas diferenças, sim, ajudam a compreender o que está acontecendo. O que Ovídio está dizendo aqui é que suas experiências são, inclusive, piores do que aquilo que é tão conhecido. Poder dizer isso faz parte, aliás, da busca pela autoridade poética. De fato, é sua autoridade como poeta que outorga a possibilidade de usar um lugar comum da linguagem e da tradição como próprio, adicionando peculiaridades de sua poesia e remarcando, a um só tempo, a superioridade sobre esse passado.

É o que se dá de forma ostensiva, por exemplo, nos casos em que Ovídio se compara com Ulisses $^{32}$, chegando muitas vezes a se distinguir, ao afirmar que ele mesmo tem sofrido e sofre mais do que o herói. Ovídio, inclusive, transcende a autoridade de Homero, já que o poeta grego apenas conta uma ficção (Tr. 1. 5. 79: adde, quod illius pars maxima ficta laborum ["agrega que a maior parte de suas dificuldades são ficção"]). Ovídio, por sua vez, descreve fatos reais, e não fabulae (Tr. 1. 5. 80: ponitur in nostris fabula nulla malis ["em nossos mais não se supõe nenhuma fábula"]). Outro caso em que Ovídio demonstra superioridade a respeito de um autor consagrado se dá na descrição de Cítia, em Tr. 3. 10, mencionada anteriormente. Modelada sobre Virgílio, G. 3.349-383, em sua construção da paisagem tomitana, Ovídio adiciona detalhes e apresenta correções à descrição virgiliana. Neste caso, a autoridade de Ovídio é potencializada pela sua qualidade de testemunha de primeira mão daquilo que está contando, por sua utilização do recurso da "autópsia"33. Este é um tipo de autoridade que Ovídio adquire graças ao fato de ser um exilado. Como testemunha ocular, pode descrever o que vê e o quê, por exemplo, não viu. Como desterrado, pode contar, melhor do que qualquer outro, sobre a experiência disruptiva que representa o exílio. Assim, mediante a revisão, releitura e correção possibilitadas pelo filtro da relegatio, Ovídio remodela os exemplos da tradição, propondo-se a si mesmo como autoridade sobre o exílio.

\section{Referencias bibliográficas:}

AMANN, M. Komik in den Tristien Ovids. Schweizerische Beiträge zur Altertumswissenschaft, Bd. 31, Basel: Schwabe, 2006.

ANDRÉ, J. Epistulae ex Ponto (Pontiques). Texte établi et traduit par J. ANDRÉ. Paris: Belles Lettres, 1977.

AUHAGEN, U. Rhetoric and Ovid. In: DOMINIK, W.; HALL, J. (ed.) A companion to Roman rhetoric. Malden, MA, Oxford: Blackwell, 2007, pp. 413-424.

\footnotetext{
${ }^{32}$ O paralelismo entre Ovídio e Ulisses tem sido muito estudado. Ver, a modo de exemplo, Davisson (1982), Tola (2000), Amann (2006), entre muitos outros.

33 Ver nota 8.
} 
BAEZA ANGULO, E. Ovidio. Tristezas. Introducción, edición crítica y traducción. Madrid: Alma Mater, 2005.

BERNHARDT, U. Die Funktion der Kataloge in Ovids Exilpoesie. Hildesheim- Zürich- New York: OLMS, 1986.

CANTER, H. V. The Figure ADYNATON in Greek and Latin Poetry. AJP 51, 40, 1930, pp. 32-41.

CARDOSO, I. T. Metamorfoses no Actéon de Ovídio. In: LEITE, N. V. de A. (Org.). Corpo e

Linguagem - A Estética do Desejo. Campinas: Mercado das Letras, v. 1, 2005, pp. 45-62.

CLAASSEN, J. M. Ovid's poems from exile: the creation of a myth and the triumph of poetry. A\&A, 34, vol. 2, 1988, pp. 158-69.

CLAASSEN, J. M. Displaced Persons: The Literature of Exile from Cicero to Boethius. London: Duckworth, 1999.

CLAASSEN, J. M. Ovid Revisited: The Poet in Exile. London: Bristol Classical Press, 2008.

DAVISSON, M. H. T. Omnia Naturae Praepostera Legibus Ibunt: Adunata in Ovid's Exile Poems. The Classical Journal, v. 76, n. 2, 1980, pp. 124-128.

DAVISSON, M. H. T. 'Duritia' and Creativity in Exile: 'Epistulae ex Ponto' 4.10. Antiquity, vol. 1, n. 1, 1982, pp. 28-42.

DELLA CORTE, F. Il reato segreto di ovidio. Cultura e scuola, vol. 29, n. 114, 1990, pp. 48-53.

DOWLING, M. B. Clemency and cruelty in the Roman world. The University of Michigan Press: Ann Arbor, 2006.

EVANS, H. B. Winter and Warfare in Ovid's Tomis: (Tristia 3.10). The Classical Journal, vol. 70, n. 3, 1975, pp. 1-9.

EVANS, H. B. Publica Carmina: Ovid's Books from Exile. Lincoln-London: University of Nebraska Press, 1983.

FANTHAM, E. Rhetoric and Ovid's Poetry. In: KNOX, P (ed.). A companion to Ovid. Malden, MA, Oxford: Blackwell, 2009, pp. 26-44.

FITTON BROWN, A. D. The unreality of Ovid's Tomitan exile. Liverpool Classical Monthly, Liverpool, v. 10, n. 2, 1985, pp. 18-22.

GAERTNER, J. F Ovid, Epistulae ex Ponto, Book 1. Oxford Classical Monographs, Oxford: Oxford University Press, 2005.

GALASSO, L. P. Ovidii Nasonis, Epistularum ex Ponto liber II. Florence: Le Monnier, 1995.

GRAF, F. Myth in Ovid. In: HARDIE, Ph. (ed.) The Cambridge Companion to Ovid. Cambridge: Cambridge University Press, 2002, pp. 108-121.

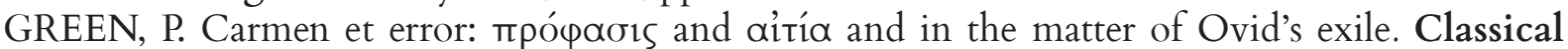
Antiquity, 1, 1982, pp. 202-220.

HARDIE, Ph. Virgil's Aeneid. Cosmos and Imperium. Oxford: Clarendon Press, 1986.

HASEGAWA, A. P. Quando os historiadores mentem e os poetas dizem verdades: 'ficção' e verdade na Antiguidade. Revera, vol. 2, 2017, pp. 7-26.

HELZLE, M. Publii Ovidii Nasonis Epistularum ex Ponto liber IV. Hildescheim: Olms, 1989.

HINDS, S. Allusion and intertext. Dynamics of appropriation in Roman Poetry. Cambridge: Cambridge University Press, 1998.

INGLEHEART, J. Ovid, the Error and the Theme of Sight in Tristia 2. MD, n. 56, 2006, pp. 63-86.

INGLEHEART, J. Commentary on Tristia Book II. Oxford: Oxford University Press, 2010.

LAROSA, B. The Mythical exempla of Faithful Heroines in Seneca the Elder's ork: Literary Occurrences of a Declamatory Device. In: DINTER, M.; GUERIN, C.; Santos, M. M. (eds.) Reading Roman Declamation. Seneca the Elder. Oxford: Oxford University Press, 2020, pp. 186-200.

LECHI, F. Testo mitologico e testo elegiaco. A proposito dell'exemplum in Properzio. MD, n. 3, 1979, pp. 83-100. 
LOWRIE, M. Writing, Performance, and Authority in Augustan Rome. Oxford: Oxford University Press, 2009.

LUCK, G. P. Ovidius Naso, Tristia. Band I. Herausgegeben, übersetzt und erklärt von G. LUCK. Heidelberg: Carl Winter, 1967.

MCGOWAN, M. Ovid in Exile. Power and Poetic Redress in the Tristia and Epistulae ex Ponto. Leiden-Boston: Brill, 2009.

NAGLE, B. R. The Poetics of Exile: Program and Polemic in the Tristia and Epistulae ex Ponto of Ovid. Bruselas: Latomus, vol. 170, 1980.

NATOLI, B. Silenced voices. The Poetics of Speech in Ovid. Madison: The Wisconsin University Press, 2017.

NEWMAN, J. K. The concept of Vates in Augustan poetry. Bruselas: Latomus, revue d'études latines, 1967.

PETERSEN, A. Ovid's wife in the Tristia and the Epistulae ex Ponto. Transforming erotic elegy into conjugal elegy. Dissertação de Mestrado, Universidade de Georgia, 2005.

POEL, M. van der. The Use of exempla in Roman Declamation. Rhetorica, vol. 27, n.3, 2009, pp. 332-353.

PUTNAM, M. Ovid, Virgil and Myrrha's Metamorphic Exile. Vergilius (1959-), vol. 47, 2001, pp. 171-193.

RAHN, H. Ovids elegische Epistel. A\&A 7, 1958, pp. 105-120.

REEBER, J. The Lady and the tiger: generic play in Tristia 1. 6. Ponência apresentada na $110^{\text {th }}$ Metting of the Classical Association of the Middle West and South, 2014.

ROSATI, G. L'elegia al femminile: le Heroides di Ovidio (e altre heroides). MD, n. 29, 1992, pp. 71-94.

SCANLON, L. Narrative, authority, and power. The Medieval exemplum and the Chaucerian tradition. Cambridge: Cambridge University Press, 2007.

SCHIESARO, A. Ovid and the professional discourses of scholarship, religion, rhetoric. In: HARDIE, Ph. The Cambridge companion to Ovid. Cambridge: Cambridge University Press, 2002, pp. 62-78.

SCHNIEBS, A.; DAUJOTAS, G. El arte de amar. Texto latino, introducción y notas. Colihue: Buenos Aires, 2009.

SYME, R. History in Ovid. Oxford: Oxford University Press, 1978.

THIBAULT, J. C. The Mystery of Ovid's Exile. Berkeley-Los Angeles: UC Press, 1964.

TISSOL, G. Ovid. Epistulae ex Ponto, book I. Edited by Garth Tissol. Cambridge: Cambridge University Press, 2014.

TOLA, E. La métamorphose poétique chez Ovide: Tristes et Pontiques. Le poème inépuisable. Paris-Louvain- Dudley, Ma.: Peeters, 2000.

TOLA, E. Ovide-Actéon: les risques métamorphiques du regard des Métamorphoses aux Tristes. Euphrosyne, 36, 2008, pp. 37-48.

UGARTEMENDÍA, C. M. A exemplaridade do abandono: epístola elegíaca e intratextualidade nas Heroides de Ovídio. Dissertação de Mestrado em Letras Clássicas, FFLCH, USP, São Paulo, 2017.

WILSON, D. Irony, Hyperbole, Jokes and Banter. In: BLOCHOWIAK, J.; GRISOT, C.; DURRIEMANN, S. \& LAENZLINGER, C. (eds.) Formal Models in the Study of Language: Applications in Interdisciplinary Contexts. Springer, 2017, pp. 201-220.

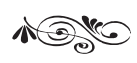

